\title{
Effect of a Novel Stent on Re-Endothelialization, Platelet Adhesion, and Neointimal Formation
}

\author{
Hanfei Tang ${ }^{1}$, Qi Wang ${ }^{1}$, Xiaobo Wang ${ }^{2}$, Jianping Zhou ${ }^{3}$, Mengjiao Zhu ${ }^{4}$, Tong Qiao ${ }^{1}$, Changjian Liu ${ }^{1}$, \\ Chun $\mathrm{Mao}^{2}$ and Min Zhou ${ }^{1}$ \\ ${ }^{1}$ Department of Vascular Surgery, Nanjing Drum Tower Hospital, The Affiliated Hospital of Nanjing University Medical School, \\ Nanjing, P.R. China \\ ${ }^{2}$ College of Chemistry and Materials Science, Nanjing Normal University, Nanjing, P.R. China \\ ${ }^{3}$ Department of General Surgery, Yixing People’s Hospital, Yixing, P.R. China \\ ${ }^{4}$ Department of Oral Sciences, Institute and Hospital of Stomatology, Nanjing University Medical School, Nanjing, P.R. China
}

\begin{abstract}
Aim: Vascular endothelial-cadherin (VE-cadherin) is specifically expressed by outgrowth endothelial cells (OECs). Zwitterionic stent showed high antifouling and excellent blood compatibility. Therefore, we hypothesized that anti-VE-cadherin antibody-coated zwitterionic stents (VE-cad-Z stents) would promote re-endothelialization, reduce neointimal formation, and resist thrombus.

Methods: VE-cad-Z stents were examined using platelet adhesion test, platelet activation, and OEC capture ability in vitro. In vivo effect of $\mathrm{VE}-$ cad-Z stents on re-endothelialization, thrombus-resistance, and neointima hyperplasia was investigated in left common carotid arteries of rabbits $(n=15)$. Results: In vitro, VE-cad-Z stents showed better platelet-resistance and OEC-capture ability (DNA concentration: $297.23 \pm 22.71$ versus $67.49 \pm 15.26 \mathrm{ng} / \mu \mathrm{L}, P<0.01)$. In vivo, $\mathrm{VE}$-cad-Z stents exhibited better patency rate than bare metal stents (BMS) (15/15 versus 12/15), and it significantly reduced platelet adhesion and neointima formation (neointima area: $1.13 \pm 0.05$ versus $1.00 \pm 0.05$ $\mathrm{mm}^{2}, P<0.01$ and $3.04 \pm 0.11$ versus $1.05 \pm 0.06 \mathrm{~mm}^{2}, P<0.01$, at 3 and 30 days, respectively; \% stenosis: $20.99 \pm 0.98$ versus $18.72 \pm 0.97, P<0.01$ and $56.46 \pm 2.20$ versus $19.45 \pm 1.24, P<0.01$, at 3 and 30 days, respectively).

Conclusion: These data suggested that VE-cad-Z stents could specifically capture OECs, consequently promote endothelial healing, and also reduce platelet adhesion and neointima formation.
\end{abstract}

See editorial vol. 23: 46-47

J Atheroscler Thromb, 2016; 23: 67-80.

Key words: Small diameter stent, Vascular endothelial-cadherin, Zwitterionic structures, Restenosis, Re-endothelialization

\section{Introduction}

Drug eluting stents (DES) have greatly reduced in-stent restenosis (ISR) rate of small diameter disease. However, these anti-healing stents interfere with the process of natural vascular healing by preventing or delaying the formation of a functional endothelial

Address for correspondence: Min Zhou, Department of Vascular Surgery, Nanjing Drum Tower Hospital, The Affiliated Hospital of Nanjing University Medical School, Nanjing 210008, P.R. China

E-mail: zhouminnju@126.com

Received: May 5, 2015

Accepted for publication: July 25, 2015 monolayer over the stents and thus cause some serious safety problems like stent thrombosis and neointimal proliferation ${ }^{1-3)}$.

Previous studies suggested that rapid re-endothelialization of the stented area could reduce the risk of inflammation and subsequent thrombus formation ${ }^{4}$. Therefore, the endothelial progenitor cells (EPCs) capture stents (Genous ${ }^{\mathrm{TM}}$ Bio-Engineered R Stent, OrbusNeich, Fort Lauderdale, Florida) coated with anti-human CD34 monoclonal antibody have been developed and shown to enhance endothelialization $^{5-7)}$. However, CD34-positive cells are capable of differentiating into different kinds of cells including inflammatory cells and vascular smooth muscle cells 
$(\mathrm{SMCs})^{8-10)}$. This problem, the lack of specificity to capture EPC, may explain the increased ISR of Genous $^{\mathrm{TM}}$ Bio-Engineered R Stent ${ }^{11,12)}$. Therefore, cell-specific molecular targeting EPC-capture without activation of platelets or recruitment of inflammatory cells and vascular SMC is important for developing more efficient and safer DES in the future.

Recently, J.M. Lee et al. carried out a head-tohead comparison between anti-CD34 antibody-coated stents and anti-VE-cadherin antibody-coated stents. The results revealed that anti-VE-cadherin antibodycoated stent could capture circulating outgrowth endothelial cells (OECs) and endothelial cells more effectively and specifically in vitro and in vivo ${ }^{13)}$. Moreover, VE-cadherin is specifically expressed in adherent junctions of endothelial cells and performs important functions such as intracellular signaling and cell-cell adhe$\operatorname{sion}^{14)}$. Therefore, we hypothesized that VE-cadherin may be an ideal target surface marker for capturing EPC.

Our previous study showed that zwitterionic stent had high antifouling and excellent blood compatibility using tests such as platelet adhesion tests, hemolysis assay, coagulation time tests ${ }^{15}$. Therefore, in the present study, we applied anti-VE-cadherin antibody to our newly developed zwitterionic stents. We hypothesized that these VE-cad-Z stents may enhance reendothelialization and resist thrombus effectively.

\section{Materials and Methods}

\section{Fabrication of VE-cad-Z Stents}

Bare metal stents (BMS) were purchased from Yinyi Co. (Dalian, China), and all chemical reagents and solvents without specific note were purchased from Sigma-Aldrich Chemical Co (St. Louis, MO). BMS-CuBr stents with atom transfer radical polymerization (ATRP) functionalities were prepared as previously described ${ }^{16)}$. For the preparation of polyethylene glycol methacrylate (PEGMA) brushes on the BMSBr surface, PEGMA ( $8 \mathrm{ml}, 24.6 \mathrm{mmol}), \mathrm{CuBr}(0.0360$ g, $0.246 \mathrm{mmol}), \mathrm{CuBr}_{2}(0.0120 \mathrm{~g}, 0.0500 \mathrm{mmol})$, bpy $(0.0760 \mathrm{~g}, 0.492 \mathrm{mmol})$ in $8 \mathrm{ml}$ of DMF was added in a three-neck flask. After three cycles of filling and deflating gas, the reaction proceeded with a protection of argon at $35^{\circ} \mathrm{C}$ for $4 \mathrm{~h}$. The resulting surface was rinsed using copious amounts of DMF, ethanol, and deionized water, followed by drying under reduced pressure. For the production of BMS-poly(ethylene glycol)-2-ethacryloxyethyl phosphorylcholine (BMSPEG-MPC) stents, the reaction was carried out using $\mathrm{CuBr}(0.057 \mathrm{~g}, 0.390 \mathrm{mmol})$, bpy $(0.125 \mathrm{~g}, 0.809$ $\mathrm{mmol})$, MPC (2.36 g, $7.99 \mathrm{mmol})$ in $7.5 \mathrm{ml}$ metha- nol under an argon atmosphere at room temperature for $24 \mathrm{~h}$. BMS-PEG-MPC was washed thoroughly using ethanol and deionized water to ensure complete removal of the physically adsorbed reactants, before drying in a vacuum desiccator under reduced pressure overnight. Finally, $10 \mu \mathrm{g}$ of mouse monoclonal antihuman VE-cadherin antibody (ab155350, Abcam) was used in antibody adsorption after BMS-PEG-MPC in $50 \mathrm{ml}$ MES buffer $(0.05 \mathrm{~mol} / \mathrm{l}, \mathrm{pH} 5.60)$ reacted with $100 \mathrm{mg}$ EDC and $60 \mathrm{mg}$ NHS for $10 \mathrm{~min}$.

\section{Platelet Adhesion Test in vitro}

The BMS and VE-cad-Z stents were placed into cell culture plates. To equilibrate BMS and VE-cad-Z stents, $1 \mathrm{~mL}$ of phosphate buffered solution (PBS) was added in each well and allowed to remain for $12 \mathrm{~h}$. After removing the PBS, $1 \mathrm{~mL}$ of freshly prepared platelet rich plasma (PRP) of human blood, which was prepared from citrated fresh human blood, was dropped on each well and allowed to remain for 90 min at $37^{\circ} \mathrm{C}$. The PRP was removed using an aspirator, and each well was rinsed three times with $1 \mathrm{~mL}$ of PBS. Then, $1 \mathrm{~mL}$ of $2.5 \mathrm{vol} \%$ glutaraldehyde in PBS was added in each well, and the materials were maintained at room temperature for $30 \mathrm{~min}$ to fix the platelets on the stents. The stents were washed with PBS again and then subsequently dehydrated by systemic immersion in a series of ethanol-water solutions $[50,60,70,80,90,95$, and $100 \%(\mathrm{v} / \mathrm{v})]$ for 30 min each and allowed to evaporate at room temperature. The surfaces of stents with platelets were observed using a scanning electron microscope (SEM, Model S-2260N; Hitachi Co. Ltd.). For SEM, six identical specimens were observed, and the presented images are representative.

\section{Platelet Activation in vitro}

To measure the platelet activation, the PRP was incubated at $37^{\circ} \mathrm{C}$ with four types of samples. The incubation mixture was removed at $30 \mathrm{~min}$ to assess the activation state of the platelets by flow cytometry. Expression of the fluorescently labeled platelet activation marker anti-CD62P and platelet pan-marker anti-CD42a was detected using a BD FACSCalibur (BD Biosciences, USA). All the platelet activation experiments were conducted in triplicate.

\section{Preparation of OECs}

OECs were prepared as previously described ${ }^{17)}$. In brief, human peripheral blood mononuclear cells (PBMCs) were re-suspended in culture medium after isolation. The PBMCs $\left(1 \times 10^{7} /\right.$ well $)$ were then immediately plated on collagen type I (BD Biosciences)- 


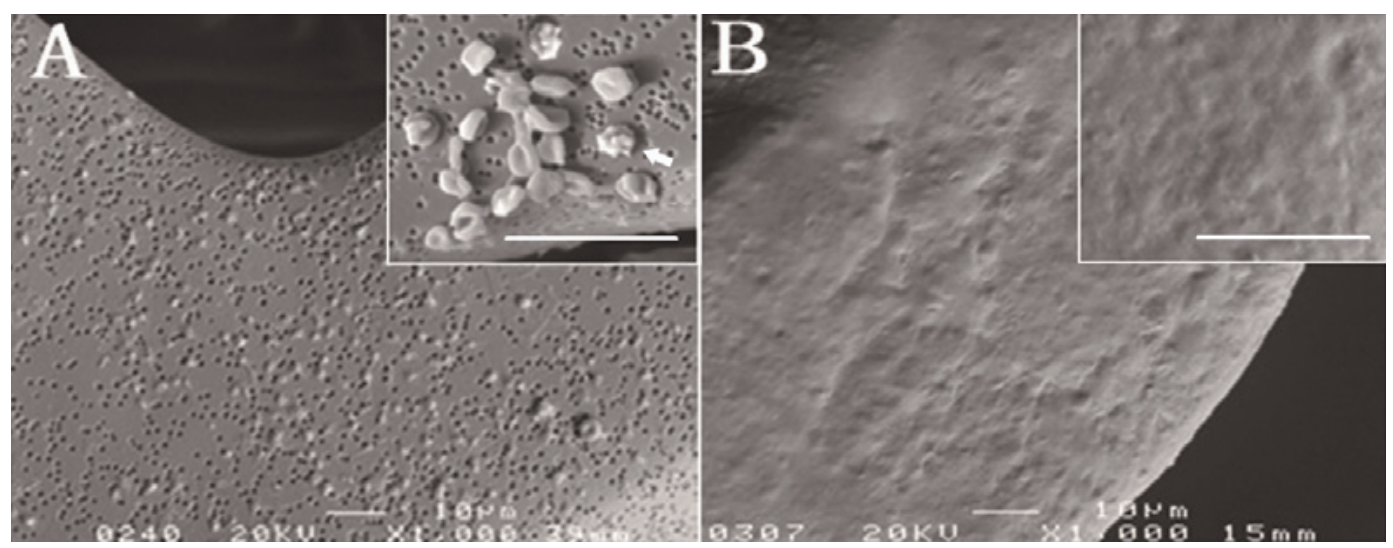

Fig. 1. Comparison of platelet adhesion on BMS and VE-cad-Z stents.

A, Representative SEM image of BMS after contact with PRP for $90 \mathrm{~min}$. B, Representative SEM image of VE-cad-Z stents after contact with PRP for $90 \mathrm{~min}$. Inserts show high-power SEM images of the stent surface.

White arrow in the image denotes platelets. Bar $=10 \mu \mathrm{m}$.

coated 35-mm diameter tissue culture plates (BD Biosciences). Medium was changed daily for 7 days and then every other day till the first passage. To further confirm the OECs phenotype, the cultured cells were incubated with monoclonal antibodies against CD31PE, CD144-PE, CD34-PE (BD Bioscience), CD14FITC, CD45-FITC (Immunotech), and CD133-PE (R\&D Systems) and analyzed using a fluorescenceactivated cell sorting (FACS) flow cytometer and WinMDI software (Becton Dickinson).

\section{Evaluation of OECs Capture in vitro}

The dynamic culture was followed as previously reported $^{18)}$. In brief, 10 BMS and $10 \mathrm{VE}$-cad-Z stents were connected to a circulatory loop system, which consisted of a roller pump (Zhisun Instrument Co., Ltd.) upstream of the graft and an outflow reservoir downstream of the graft. The stent was tied to the circulatory loop, and the circulatory loop was filled with culture medium $\left(2 \times 10^{6} \mathrm{OECs} / \mathrm{ml}\right)$. Medium flowed from the roller pump through the stent to the outflow reservoir. Medium in the outflow reservoir was pumped up using the roller pump and recirculated. To simulate physiological flow rates, the pump setting was 70 strokes $/ \mathrm{min}$, which yielded a flow rate of $60 \mathrm{~mL} / \mathrm{min}$. At this flow rate, the calculated shear stress at the graft was $30 \mathrm{dyn} / \mathrm{cm}^{2}$. The entire system was installed in an incubator at $37^{\circ} \mathrm{C}$ in a humidified environment with $5 \% \mathrm{CO}_{2}$. After $24 \mathrm{~h}$ of perfusion, the stents were retrieved for SEM observation.

DNA quantification was used to estimate the OEC-capture ability of BMS and DES. The QIAmp AllPrep DNA mini kit (Qiagen, Milan, Italy) was used for DNA preparation. DNA quantity and quality was analyzed by reading the whole absorption spectrum $(220-750 \mathrm{~nm})$ with NanoDrop ND-2000 and calculating DNA concentration and absorbance ratio at both $260 / 280$ and $230 / 260 \mathrm{~nm}^{19)}$. To further confirm the viability of the captured OECs, they were labeled with calcein AM and DAPI staining. For this purpose, stents were washed with $1 \times \mathrm{PBS}, \mathrm{pH} 7.4$ (Invitrogen), followed by staining with calcein AM $(2 \mu \mathrm{M})$ (Invitrogen) for $45 \mathrm{~min}$ at room temperature. After the removal of free calcein by washing with Hank's balanced salt solution (HBSS), the staining facilitated observation of live cells. Thereafter, cells were fixed with 4\% PBS-buffered paraformaldehyde (15 min), washed twice in HBSS, and stained with 406-diamino2-phenylindole (DAPI, $0.05 \mathrm{mg} / \mathrm{ml} \mathrm{HBSS}$, Sigma) for $15 \mathrm{~min}$ to observe the nuclear morphology.

\section{Surgical Implantation in vivo}

All care and handling of the animals were provided according to the Guide for the care and use of Laboratory Animals approved by the Ethical Committee of Researches of Nanjing University.

In brief, 30 male rabbits (New Zealand white) with a body weight between 3.5 and $4.0 \mathrm{~kg}$ were randomly implanted with BMS $(n=15)$ and VE-cad-Z stents $(n=15)$ in the left carotid arteries and were followed for 3 and 30 days. Anesthesia was induced with an injection of intramuscular ketamine $(30 \mathrm{mg} / \mathrm{kg})$ and intravenous pentobarbital $(30 \mathrm{mg} / \mathrm{kg})$ and then maintained using isoflurane and oxygen. Through a longitudinal left neck incision, left common carotid artery exposed. Before arterial clamping, heparin (100 $\mathrm{U} / \mathrm{kg}$ ) was administered intravenously. Then, a BMS or VE-cad-Z stent was implanted in the left common 
carotid artery. Both stents had a nominal diameter of $2.5 \mathrm{~mm}$ and a length of $20 \mathrm{~mm}$. The closure was sutured by layers. All animals were administered 40 $\mathrm{mg}$ aspirin in combination with $75 \mathrm{mg}$ clopidogrel daily per os postoperatively. The implanted stent patency was monitored using a handle Doppler probe (HP Sonos 4500; Philips) every 3 days, and an angiograph was performed before they were harvested.

\section{Morphologic Study After Explantation}

Three days after implantation, five BMS and five VE-cad-Z stents were explanted for histological examination, and the remaining stents were explanted after 30 days of implantation. Midportion segments of the stents were fixed with $10 \%$ (vol/vol) buffered formaldehyde solution and dehydrated with a series of ethanol. The samples were embedded in resin and cut using a tungsten blade. The degree of neointimal growth was analyzed in the sections stained with hemotoxylin and eosin. The neointimal area (NA) and the area within the internal elastic lamina (IEL) were measured by computerized morphometry, which was carried out by a single observer who was blinded to the experimental protocol. All images were captured by an Olympus XI 70 microscope equipped with an Olympus Magna Fire digital camera and were analyzed using a computerized digital image-analysis system (Image-Pro Plus version 6.0, MediaCybernetics, Silver Spring, Maryland).

SEM studies were conducted using tissues processed as previously described ${ }^{20)}$. After harvest, the stents were dissected longitudinally to evaluate the luminal surface as enface, fixed in $2.5 \%$ glutaraldehyde, and processed for scanning electron microscopy for evaluation of re-endothelialization and platelet resistance. Samples were incubated with HRP-conjugated Polyclonal anti-von Willebrand factor (vWF) antibody (DakoCytomation), followed by visualization with diaminobenzidine (Sigma) to characterize the endothelium of the stents.

\section{Western Blot Analysis}

Vessel wall expression of proteins such as endothelial nitric oxide synthase (eNOS), $\alpha$-smooth muscle actin ( $\alpha$-SM Actin), and monocyte chemoattractant protein-1 (MCP-1) was determined using western blot analysis. In brief, the stent struts were carefully removed from the coronary arteries after harvest. Then, protein extracts $(50 \mu \mathrm{g})$ were size fractionated on SDS-polyacrylamide gels and transferred to nitrocellulose membrane (Bio-Rad, Hercules, CA). Positive expression was analyzed using antibodies against eNOS (abcam, ab95254), $\alpha$-SM Actin (abcam, ab7817), and
A

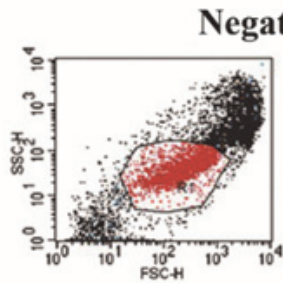

Negative control
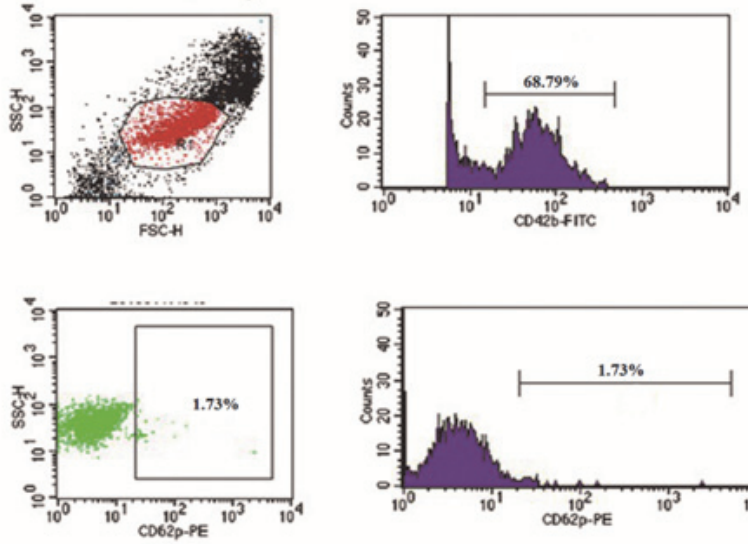

B

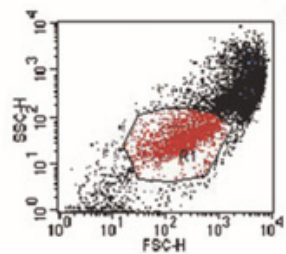

BMS
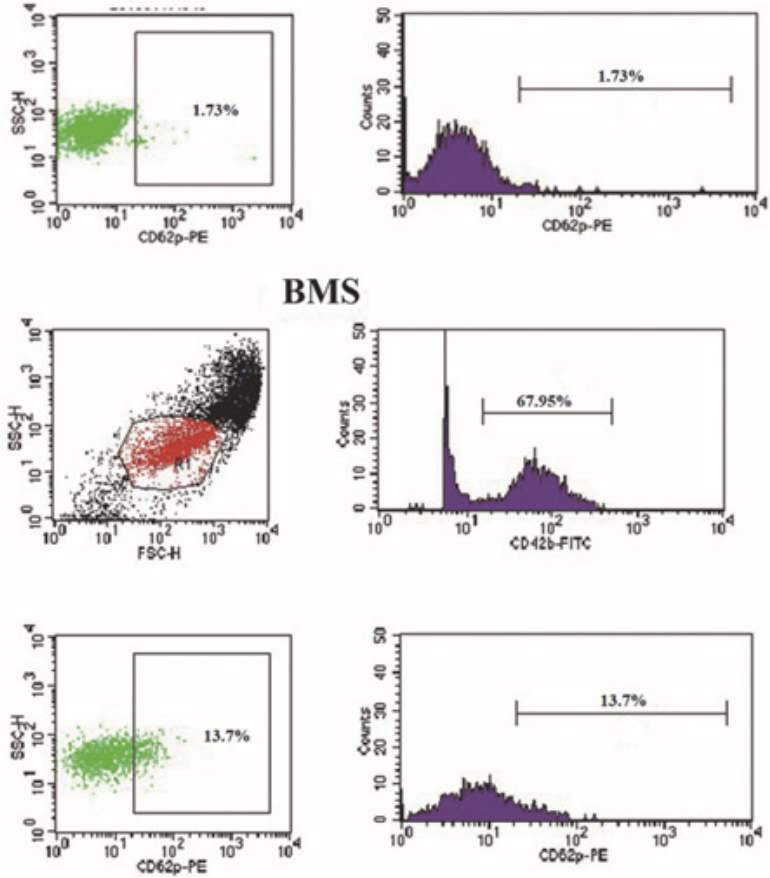

C

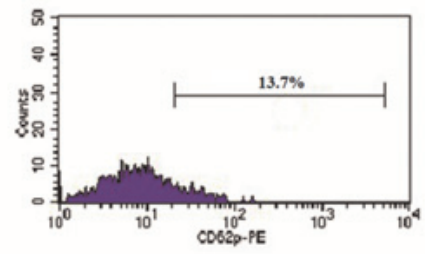

VE-cad-Z stents
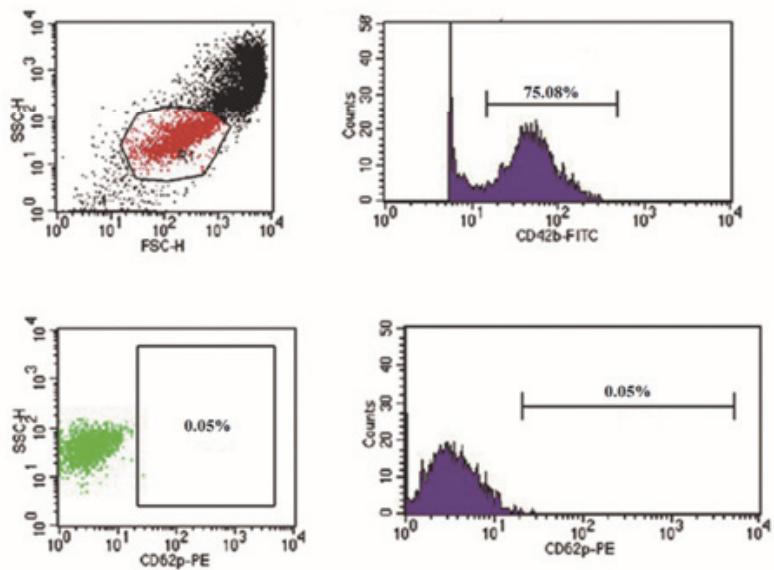

Fig. 2. Characterization of the adhered platelets on VE-cad-Z stents and BMS.

A, The representative figure of FACS data to assess the proportion of the activated platelet on the negative control. B, The representative figure of FACS data to assess the proportion of the activated platelet on BMS. C, The representative figure of FACS data to assess the proportion of the activated platelet on VE-cad-Z stents. The expression of the platelet activation marker anti-CD62PFITC on platelets was defined as $\%$ of platelet activation. 

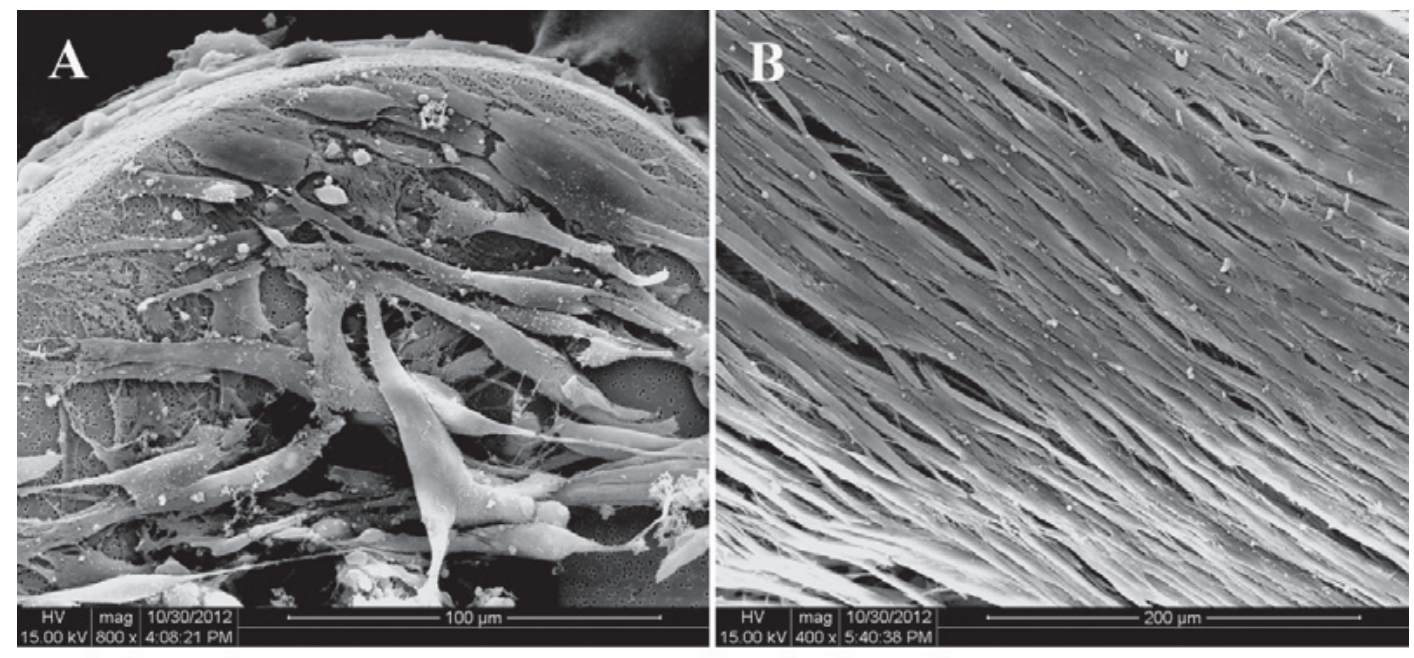

C

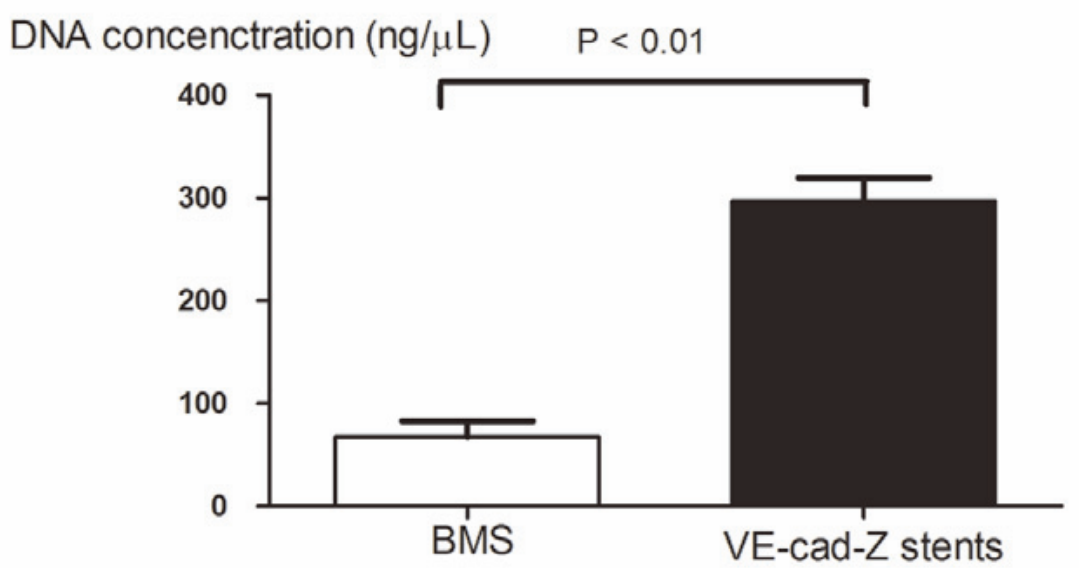

Fig. 3. Comparison of OECs capture ability between VE-cad-Z stents and BMS.

A-B, Representative SEM image of BMS (Fig. 3A) and VE-cad-Z stents (Fig. 3B) $24 \mathrm{~h}$ after dynamic culture with OECs. C, DNA quantification $24 \mathrm{~h}$ after dynamic culture with OECs. For statistical analysis, unpaired $t$-test was performed.

MCP-1 (abcam, ab18678). Horseradish peroxidaseconjugated donkey anti-rabbit antibody (Santa Cruz Biotechnology) or rabbit anti-mouse antibody (Santa Cruz Biotechnology) were used as the secondary antibody at a dilution of 1:2000. Antibody binding was detected on X-ray films using an enhanced chemiluminescence method. $\beta$-actin on the same membranes was used as a constitutive marker. Quantity One software (Bio-Rad) was used to determine the results of the densities.

\section{Statistical Analysis}

Data were analyzed using SPSS 21.0 (IBM Corp., Armonk, USA). Quantitative data were expressed as mean \pm SD. Statistical analysis of differences between two groups was performed using unpaired $t$-test, and the statistical analysis of differences among three or more groups was assessed using ANOVA and multiple comparison tests. A $p$-value of less than 0.05 was considered statistically significant.

\section{Results}

\section{Platelet Adhesion Test in vitro}

To assess preliminary blood compatibility, the platelet adhesion on BMS and VE-cad-Z stents was evaluated by SEM observation. The surfaces of BMS were porous. After contact with PRP for $90 \mathrm{~min}$, the 


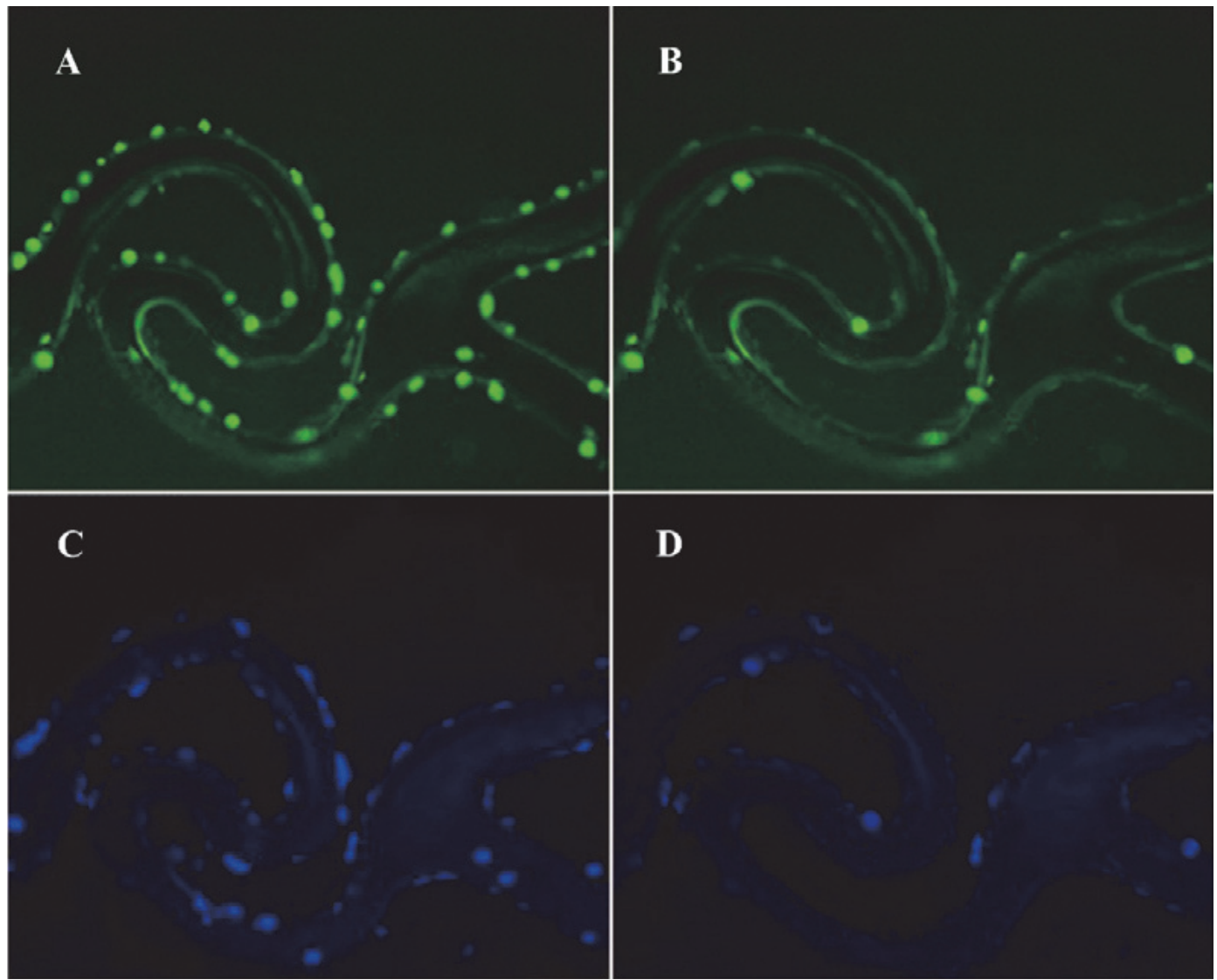

Fig. 4. Identification of OECs and viability assessment $24 \mathrm{~h}$ after dynamic culture.

A-B, Representative DAPI staining image of VE-cad-Z stents (Fig. 4A) and BMS (Fig. 4B). C-D, Representative calcein-AM staining image of VE-cad-Z stents (Fig. 4C) and BMS (Fig. 4D).

surfaces of BMS were covered with platelets. The adhered platelets were highly activated with the characteristics of spreading, aggregation, and pseudopodia (Fig. 1A). However, the surfaces of VE-cad-Z stents were smooth, and the platelet adhesion degree decreased substantially once the zwitterionic polymer brushes were grafted onto BMS. Almost no platelets were adhered on the stent (Fig. 1B).

\section{Platelet Activation in vitro}

Activated platelets were characterized by plasma membrane display of markers such as CD62P as well as by aggregation state. We measured the platelet activation after incubating the samples in PRP for $30 \mathrm{~min}$ at $37^{\circ} \mathrm{C}$ using Flow cytometry. The BMS caused significant platelets activation; platelet activation was $13.7 \%$ higher than the negative control (1.73\%) (Fig. 2A and B). After surface modification, approximately $0.05 \%$ of the platelets were activated (Fig. 2C).

\section{OECs Capture in vitro}

OECs capture ability of VE-cad-Z stents was examined by SEM, DNA quantification, and immunofluorescent analysis. After $24 \mathrm{~h}$ dynamic culture with OECs, few OECs attached on the BMS and aligned themselves disorderly (Fig. 3A). The cells on VE-cad-Z stents spread out completely and possessed a sustainable growth capability. OECs aligned wellorganized and adhered tightly to each other to maintain the high integrity of their confluent monolayer structure, which was similar to that of the native artery (Fig. 3B). DNA quantification demonstrated that VE-cad-Z stents captured a significantly increased number of OECs than BMS (DNA concentration: $297.23 \pm 22.71$ versus $67.49 \pm 15.26 \mathrm{ng} / \mu \mathrm{L}, P<0.01$, $n=10$, Fig. 3C), which was consistent with the SEM results. In addition, immunofluorescent analysis confirmed that, in comparison with BMS, VE-cad-Z stents captured more viable OECs as evidenced by amplified calcein AM and DAPI fluorescent staining intensity (Fig. 4). 


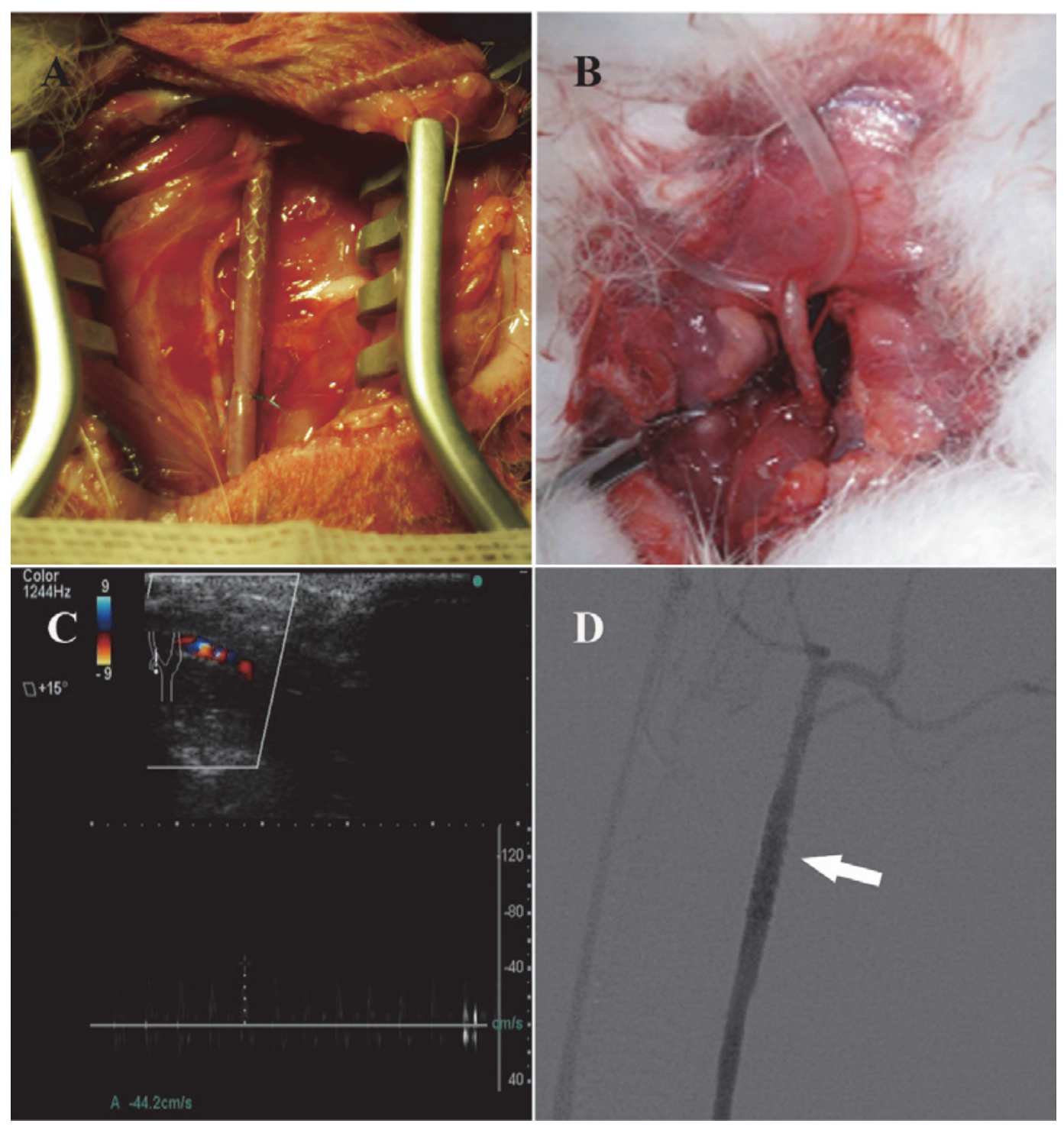

Fig. 5. A, Surgical view of stents during implantation. B, Surgical view of stents after 30 days of implantation. C, Duplex Doppler ultrasound examination of patent VE-cad-Z 30 days after implantation. D, A typical angiogram of VE-cad-Z stents 30 days after implantation. White arrow in the image denotes stented sites.

\section{Stent Patency}

Fifteen VE-cad-Z stents and 15 BMS were implanted into the carotid arteries of the rabbit. Three BMS were observed with thrombotic occlusion within 3 days by arterial Doppler ultrasound and carotid arterial angiographies, whereas all the remaining stents maintained patency till they were harvested for histological and morphometric analysis. VE-cad-Z stents exhibited excellent patency rate in vivo (Fig. 5 C and D).

\section{Platelet Resistance and Regeneration in vivo}

SEM was conducted to study in vivo effects of
VE-cad-Z stents on platelet resistance and regeneration. SEM results showed the following: (1) three days after implantation, only a few OECs attached on the luminal surface of the VE-cad-Z stents, which showed almost no difference between the BMS and VE-cad-Z stents group. Regarding the platelet adhesion, there was no platelet adhered to the VE-cad-Z stents luminal surface, whereas large number of platelets were observed on the BMS luminal surface (Fig. 6A and B). (2) Thirty days after implantation, the luminal surfaces of the VE-cad-Z stents were covered with a confluent layer of cobblestone-like cells orienting in a par- 

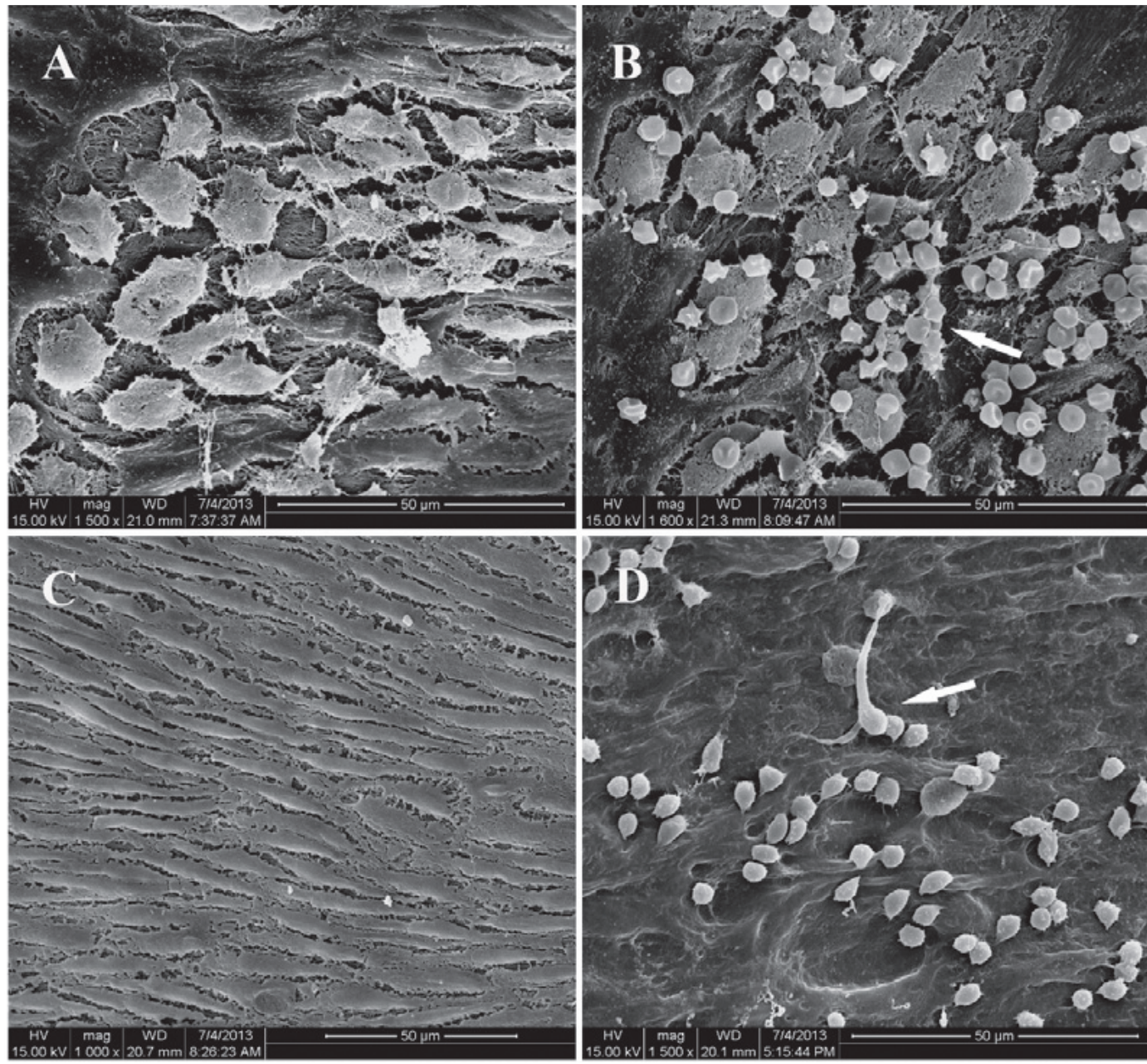

Fig. 6. Representative SEM images of the stents retrieved after implantation.

A-B, VE-cad-Z stents (Fig. 6A) and BMS 3 days after implantation (Fig. 6B). C-D, VE-cad-Z stents (Fig. 6C) and BMS (Fig. 6D) 30 days after implantation. White arrow in the image denotes thrombus.

allel manner to the direction of arterial flow without platelet adhesion. In contrast, an incomplete OECs layer and many platelets covered BMS luminal surface (Fig. 6C and D). Positive staining revealed vWF of the cells overlying the intimal layer, which was properly denoted as ECs, and the results of immunofluorescent analysis complied with SEM results (Fig.7).

\section{Neointimal Hyperplasia}

Histological and morphometric analysis was performed to access the neointimal hyperplasia. Histological analysis demonstrated the following: (1) compared with VE-cad-Z stents, a significant in-stent neointima was formed at BMS stent sites 3 days after implantation (Fig. 8A and B) (2) compared with 3 days after implantation, the neointima area of BMS increased significantly 30 days after implantation, whereas VE-
cad-Z stents showed almost the same level (Fig. 8C and D). Quantitative analysis demonstrated a significant reduction in neointima formation and stenosis at the stent site of the VE-cad-Z stents (neointima area: $1.13 \pm 0.05$ versus $1.00 \pm 0.05 \mathrm{~mm}^{2}$ and $3.04 \pm 0.11$ versus $1.05 \pm 0.06 \mathrm{~mm}^{2}$ at 3 and 30 days, respectively; $\%$ stenosis: $20.99 \pm 0.98$ versus $18.72 \pm 0.97$ and 56.46 \pm 2.20 versus $19.45 \pm 1.24$ at 3 and 30 days, respectively, Fig. 8E and F). Neointima formation and stenosis significantly increased 30 days after implantation compared with 3 days after implantation (neointima area: $1.13 \pm 0.05$ versus $3.04 \pm 0.11 \mathrm{~mm}^{2}, \%$ stenosis: $20.99 \pm 0.98$ versus $56.46 \pm 2.20$, Fig. 8E and F).

\section{Protein Expression of the Stent}

Densitometric analysis of Western blotting demonstrated that the expression of $\alpha$-SM Actin and 


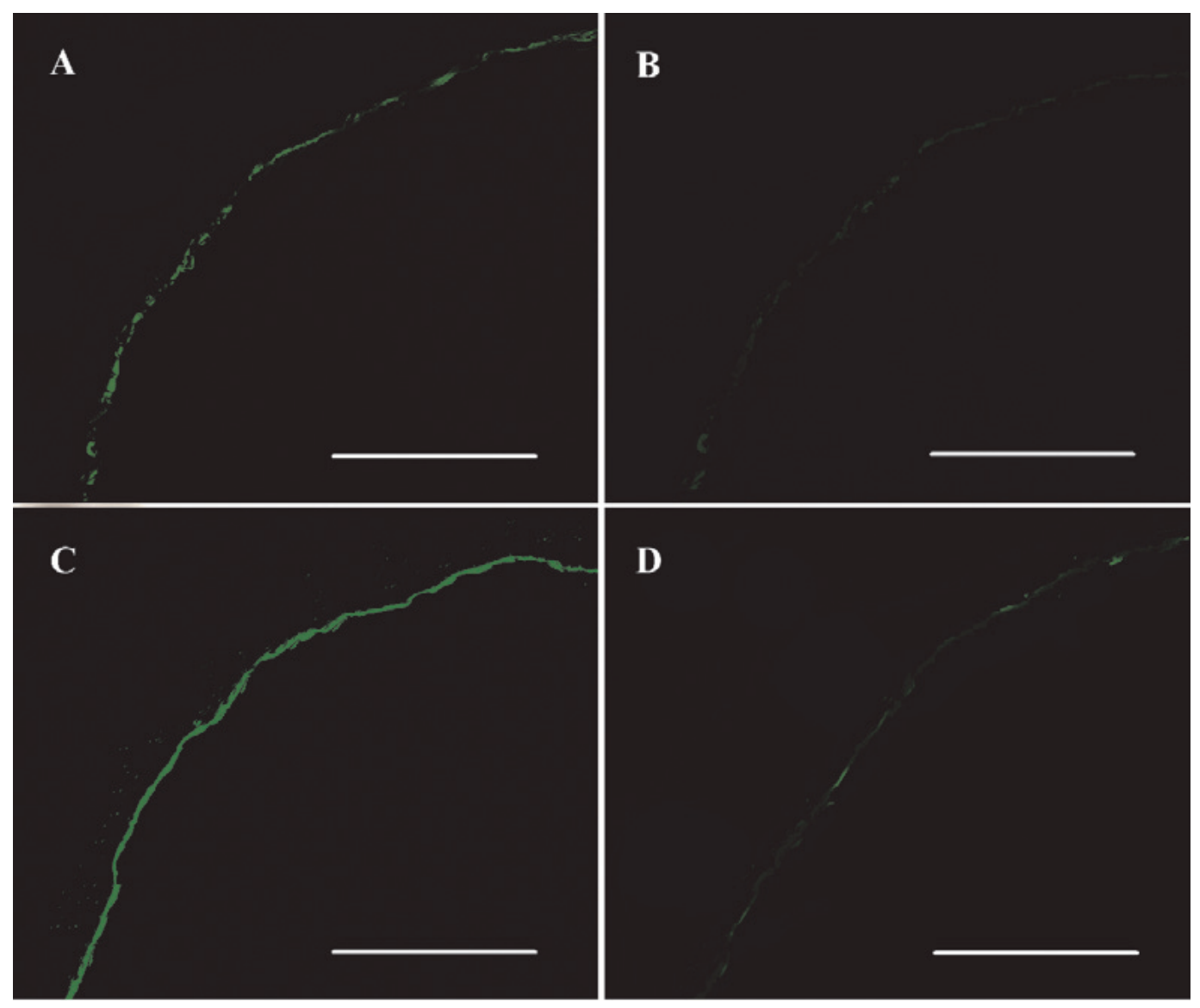

Fig. 7. Immunofluorescent staining of the stents retrieved after implantation.

A-B, Representative images of von Willebrand factor (vWF)-positive cells (green) on VE-cad-Z stents (Fig. 7A) and BMS (Fig. 7B) 3 days after implantation. C-D, Representative images of von Willebrand factor (vWF)positive cells (green) on VE-cad-Z stents (Fig. 7C) and BMS (Fig. 7D) 30 days after implantation. Bar $=0.5$ $\mathrm{mm}$.

MCP-1 in VE-cad-Z stents was significantly lower compared with BMS $(\alpha$-SM Actin: $0.51 \pm 0.09$ versus $1.50 \pm 0.15$ and MCP-1: $0.14 \pm 0.05$ versus $2.30 \pm$ 0.23 , Fig.9B). $\alpha$-SM Actin in VE-cad-Z stents showed almost the same level compared with the native carotid artery (NCA), but MPC-1 was still significantly higher than that in NCA ( $\alpha$-SM Actin: 0.51 \pm 0.09 versus $0.47 \pm 0.06$ and MCP-1: $0.14 \pm 0.05$ versus $0.06 \pm 0.03$, Fig. 9B). eNOS protein expressed in the VE-cad-Z stents was significantly higher than that in the BMS $(0.49 \pm 0.08$ versus $0.09 \pm 0.02$, Fig. 9B) and showed almost the same level compared with NCA $(0.49 \pm 0.08$ versus $0.50 \pm 0.06$, Fig.9B).

\section{Discussion}

OECs are considered to be a good candidate for vascular regenerating cell therapy, as they have much higher proliferative potential than early EPCs and marked similarity to completely differentiated ECs with regard to cellular morphology, marker expression, and the potential to form capillary-like structures ${ }^{21}$. VE-cadherin is a surface marker, which is exclusively expressed on the OECs and endothelial cells, but not on the early EPC and other leukocytes ${ }^{22}$. In our previous reports, flow cytometry analysis demonstrated that $95.8 \%$ OECs expressed VE-cadherin on their surfaces ${ }^{17)}$. Therefore, VE-cadherin may be a more ideal target surface marker for capturing EPC than CD $34^{13,23)}$. Biocompatible materials, containing zwitterion and PEG, have been identified as two important synthetic nonthrombogenic materials for DES ${ }^{24,25)}$. PEG has received much attention because of its properties of inertness for protein adsorption and cell adhesion, steric stabilization effect, and high chain mobility and low interfacial free energy ${ }^{26}$. Zwitter- 


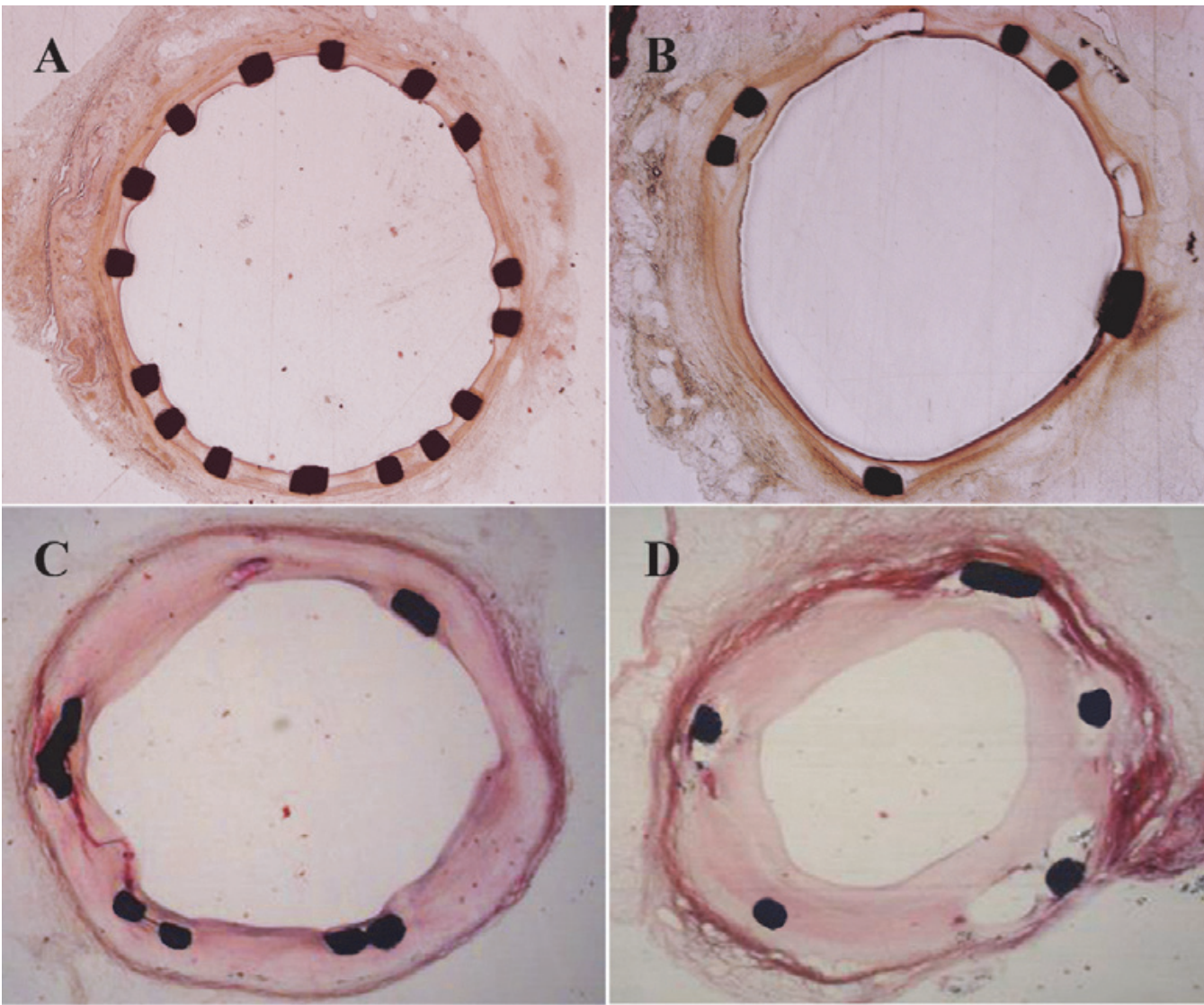

$\mathbf{E}$

$\mathbf{F}$
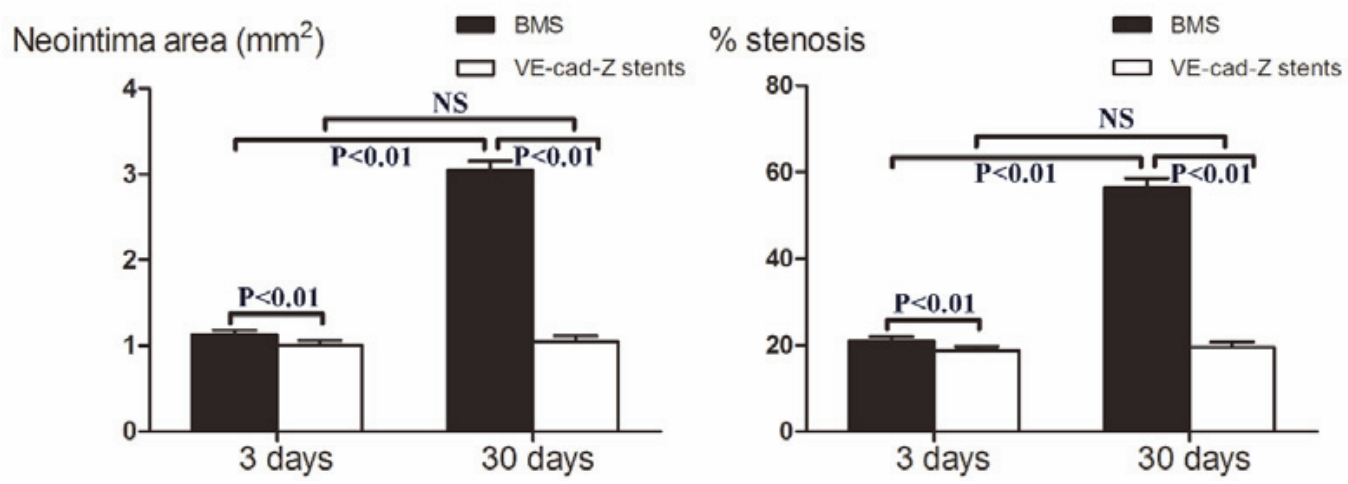

Fig. 8. Hispathological analysis of in-stent neointima formation after implantation.

A-B, Representative hematoxylin and eosin (H\&E)-stained sections of VE-cad-Z stents (Fig. 8A) and BMS (Fig. 8B) 3 days after implantation. C-D, Representative hematoxylin and eosin (H\&E)-stained sections of VE-cad-Z stents (Fig. 8C) and BMS (Fig. 8D) 30 days after implantation. E, The neointima area at BMS and VE-cad-Z stents. For statistical analysis, unpaired $t$-test was performed. F, The $\%$ stenosis $(100 \times$ area of neointima/area of internal elastic lamia) at BMS and VE-cad-Z stents. For statistical analysis, unpaired $t$-test was performed. NS = not significant.

ionic structures are designed to mimic phosphatidylcholine, which is abundant in cell membranes. These structures contain phosphorylcholine, carboxybetaine, and sulfobetaine chemistries and are effective in resisting thrombosis ${ }^{27,28)}$. Therefore, we developed a new stent using anti-human VE-cadherin antibody to coat 
zwitterionic stents.

In the present study, we demonstrated the following: (1) zwitterionic polymers resisted the platelet adherence and prevented platelet activation effectively in vitro, (2) VE-cad-Z stents could captured OECs significantly in vitro, (3) anti-VE-cadherin antibody did not affect the viability or proliferation of OECs in vitro, and (4) compared with BMS, VE-cad-Z stents reduced neointimal hyperplasia and thrombus significantly 3 and 30 days after stent implantation in the rabbit model.

The thrombotic risk for DES extends far beyond that for $\mathrm{BMS}^{29)}$, and hypersensitivity reaction to polymers on DES causes activation of thrombotic cascade resulting in stent thrombosis ${ }^{30)}$. To overcome this detrimental side effect, we designed PEG-MPC zwitterionic polymers on a molecular level and anchored PEG-MPC onto the exterior surface of BMS by ATRP functionalities. In vitro, we demonstrated that the platelets adhered on VE-cad-Z stents were significantly less than that on BMS and the platelet activation of VE-cad-Z stents was markedly lower than that of BMS. We hypothesized that the seaweed-like structure on the surface of BMS possessed the excellent ability to resist protein and platelet adhesion, and PEG-MPC zwitterionic polymers could maintain the natural structure and state of the plasma protein contact it, which may enhance platelet resistance of VEcad-Z stents.

In vitro, VE-cad-Z stents also showed excellent OEC-capture ability and biocompatibility. As a result, VE-cad-Z stent struts were covered with a confluent monolayer structure that was similar to the native artery after $24 \mathrm{~h}$ dynamic culture with OECs. The DNA concentration of the VE-cad-Z stents group was four times more than that of the BMS group, which implied that VE-cad-Z stents captured far more OECs than BMS. Moreover, DAPI and calcein staining confirmed the excellent biocompatibility of VE-cad-ZA stents. Therefore, our present data provided strong evidence that VE-cadherin may be a promising eluting layer for promoting endothelium healing. This rapid re-endothelial ability is believed to reduce neointimal hyperplasia and thrombosis in long term outcomes ${ }^{23)}$.

In addition to its remarkable performance in vitro, VE-cad-Z stents showed its advantages in vivo as well. Three BMS were found occluded by thrombus within 3 days after implantation, whereas all VE-cad$\mathrm{Z}$ stents remained patent until harvest. We hypothesized that both excellent biocompatibility of zwitterionic stent and impressive OEC-capture ability of VEcadherin contributed toward reduced in vivo thrombogenicity and improved the early patency rate of VE-
A

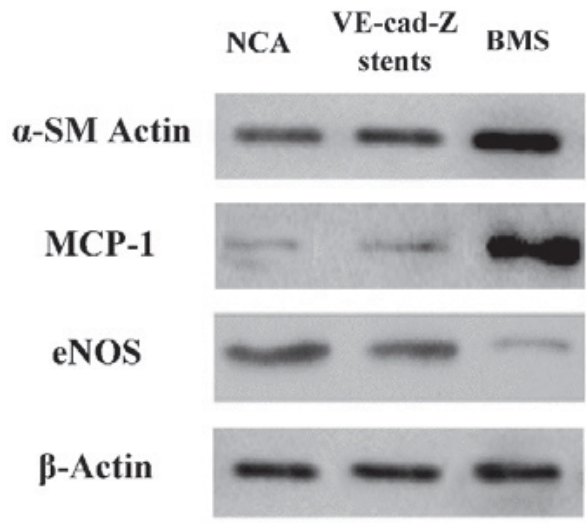

B

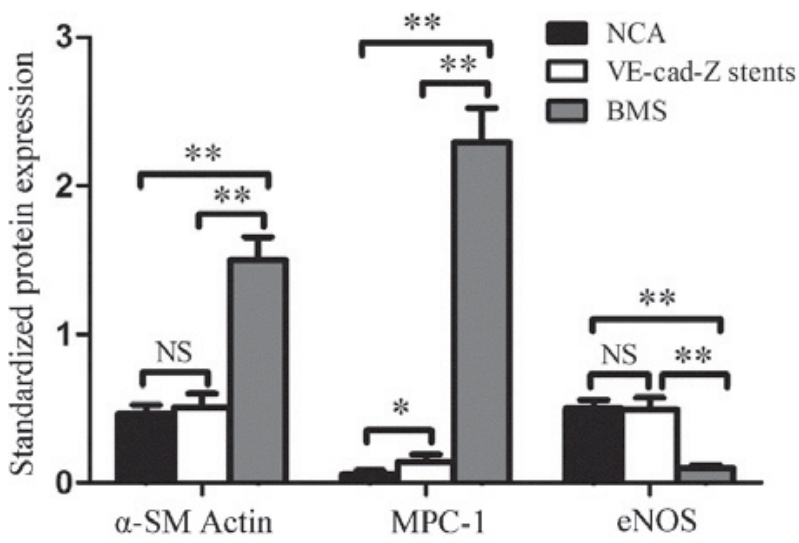

Fig.9. Protein expression of stents 30 days after implantation.

A, Photographs of immunoblots of tissue from normal coronary (NCA), BMS, and VE-cad-Z stents. B, Densitometric analysis of protein expression $(n=10$ each). For statistical analysis, one-way ANOVA was performed. ${ }^{*} P<0.05$ between two groups, ${ }^{* *} P<$ 0.01 between two groups. NS $=$ not significant.

cad-Z stents. In vivo, VE-cad-Z stents showed excellent anti-platelet ability, whereas its ability to capture OECs was comparatively unsatisfying. VE-cad-Z stents failed to capture more OECs than BMS at 3 days after implantation. Therefore, we hypothesized that VE-cadherin antibody was not specific to rabbit OECs, and this limited its ability to capture rabbit OECs. However, after 30 days of implantation, a confluent layer of OECs covered the luminal surface of VE-cad-Z stents. We hypothesized that specific platelet-resistant structure of PEG-MPC zwitterionic polymers as described above reduced the in vivo thrombogenicity and improved the early patency rate of VE- 
cad- $Z$ stents, and the compliance of the seaweed-like structure prolonged the collision time, reduced the recoil force, and helped VE-cadherin capture OECs in blood when systole or blood lashed against VE-cad-Z stents, which provided time window for VE-cad-Z stents to re-endothelization.

Apart from thrombosis, another side effect is instent restenosis (ISR), which is because of uncontrolled neointimal hyperplasia and tissue proliferation in response to vessel injury ${ }^{31)}$. Three and 30 days after stenting, histological and morphometric analysis demonstrated that employment of VE-cad-Z stents could significantly reduce neointimal formation and ISR. In addition, it is found that VE-cad-Z stents expressed a much higher level of eNOS protein and a much lower level of MCP-1 and $\alpha$-SM Actin protein than BMS, and the expression of these proteins of the VE-cad-Z stents was comparable to the native carotid artery. It is well known that MCP-1 exhibits its most potent chemotactic activity toward monocytes and $\mathrm{T}$ lymphocytes $^{32)}, \alpha$-SM Actin is present in high amounts in vascular SMC, and eNOS expression is relatively restricted to the vascular endothelium (the cell-specific expression of endothelial nitric-oxide synthase). Moreover, it is reported that the expression of eNOS is critical for functional DESs, which catalyzes the production of NO, a potent vasodilator that inhibits SMCs proliferation and migration, which are responsible for intimal hyperplasia as well as platelet aggregation and adhesion ${ }^{33}$,34). Therefore, we hypothesized that lack of functional endothelium and subsequent inflammatory cell infiltration into the injured artery caused smooth muscle cell migration and proliferation, which resulted in neointimal hyperplasia ${ }^{30)}$. Moreover, the neointimal area and ISR of BMS significantly increased with implantation time, whereas those of VE-cad-Z stents did not increase. We hypothesized that it may be because of the confluent layer of OECs that inhibit SMC migration and proliferation by a paracrine pathway ${ }^{35)}$ and thus prevented the neointimal hyperplasia. Therefore, complete re-endothelialization within a few days played an important role in the prevention of stent thrombosis and in the inhibition of neointimal growth ${ }^{13)}$.

One limitation was that we did not perform the immunohistochemical analysis of the neointimal area; thus, evaluation of macrophage infiltration and degree of proliferative activities in the neointima was not available. Another limitation was that our study was limited to observations in experimental animal models; therefore, its clinical relevance to human being was uncertain.

\section{Conclusion}

Coating VE-cadherin onto zwitterionic stents may be an attractive approach for drug-eluting stents, and VE-cadherin coated zwitterionic stents seemed capable of capturing circulating OECs and endothelial cells effectively and specifically without the activation of platelets or recruitment of inflammatory cells and vascular SMC. To the best of our knowledge, this is the first report on DES constructed by coating VEcadherin onto zwitterionic stents, and our findings provided strong evidence for the validity of our protocol. However, this is just a preliminary study of VEcad-Z stents, and many questions are still unanswered. Therefore, we are going to further study the long term outcome and side effect of our novel DES.

\section{Funding Sources}

This study was funded by grants from the National Natural Science Foundation of China (Grant No. 81201210), Top Six Talents Project of Jiangsu Province (Grant No. 2013-wsw003), the Science Project of Jiangsu Health (Grant No. Z201308), and Key Project supported by Medical Science and technology development Foundation, Nanjing Department of Health (Grant No.JQX14002).

\section{COI}

No competing financial interests exist.

\section{Reference}

1) Carter AJ, Aggarwal M, Kopia GA, Tio F, Tsao PS, Kolata R, Yeung AC, Llanos G, Dooley J and Falotico R: Longterm effects of polymer-based, slow-release, sirolimuseluting stents in a porcine coronary model. Cardiovasc Res, 2004; 63: 617-624

2) Werner N, Junk S, Laufs U, Link A, Walenta K, Bohm M and Nickenig G: Intravenous transfusion of endothelial progenitor cells reduces neointima formation after vascular injury. Circ Res, 2003; 93: e17-24

3) Kong D, Melo LG, Mangi AA, Zhang L, Lopez-Ilasaca M, Perrella MA, Liew CC, Pratt RE and Dzau VJ: Enhanced inhibition of neointimal hyperplasia by genetically engineered endothelial progenitor cells. Circulation, 2004; 109: 1769-1775

4) Kipshidze N, Dangas G, Tsapenko M, Moses J, Leon MB, Kutryk M and Serruys P: Role of the endothelium in modulating neointimal formation: vasculoprotective approaches to attenuate restenosis after percutaneous coronary interventions. J Am Coll Cardiol, 2004; 44: 733739

5) Shirota T, Yasui H, Shimokawa $H$ and Matsuda T: Fabri- 
cation of endothelial progenitor cell (EPC)-seeded intravascular stent devices and in vitro endothelialization on hybrid vascular tissue. Biomaterials, 2003; 24: 2295-2302

6) Co M, Tay E, Lee CH, Poh KK, Low A, Lim J, Lim IH, Lim YT and Tan HC: Use of endothelial progenitor cell capture stent (Genous Bio-Engineered R Stent) during primary percutaneous coronary intervention in acute myocardial infarction: intermediate- to long-term clinical follow-up. Am Heart J, 2008; 155: 128-132

7) Aoki J, Serruys PW, van Beusekom H, Ong AT, McFadden EP, Sianos G, van der Giessen WJ, Regar E, de Feyter PJ, Davis HR, Rowland S and Kutryk MJ: Endothelial progenitor cell capture by stents coated with antibody against CD34: the HEALING-FIM (Healthy Endothelial Accelerated Lining Inhibits Neointimal Growth-First In Man) Registry. J Am Coll Cardiol, 2005; 45: 1574-1579

8) Simper D, Stalboerger PG, Panetta CJ, Wang S and Caplice NM: Smooth muscle progenitor cells in human blood. Circulation, 2002; 106: 1199-1204

9) Shimizu K, Sugiyama S, Aikawa M, Fukumoto Y, Rabkin E, Libby P and Mitchell RN: Host bone-marrow cells are a source of donor intimal smooth- muscle-like cells in murine aortic transplant arteriopathy. Nat Med, 2001; 7: 738-741

10) Peichev M, Naiyer AJ, Pereira D, Zhu Z, Lane WJ, Williams M, Oz MC, Hicklin DJ, Witte L, Moore MA and Rafii S: Expression of VEGFR-2 and AC133 by circulating human CD34(+) cells identifies a population of functional endothelial precursors. Blood, 2000; 95: 952-958

11) Bystron M, Cervinka P, Spacek R, Kvasnak M, Jakabcin J, Cervinkova M, Kala P and Widimsky P: Randomized comparison of endothelial progenitor cells capture stent versus cobalt-chromium stent for treatment of ST-elevation myocardial infarction. Six-month clinical, angiographic, and IVUS follow-up. Catheter Cardiovasc Interv, 2010; 76: 627-631

12) Beijk MA, Klomp M, Verouden NJ, van Geloven N, Koch KT, Henriques JP, Baan J, Vis MM, Scheunhage E, Piek JJ, Tijssen JG and de Winter RJ: Genous endothelial progenitor cell capturing stent vs. the Taxus Liberte stent in patients with de novo coronary lesions with a high-risk of coronary restenosis: a randomized, single-centre, pilot study. Eur Heart J, 2010; 31: 1055-1064

13) Lee JM, Choe W, Kim BK, Seo WW, Lim WH, Kang CK, Kyeong S, Eom KD, Cho HJ, Kim YC, Hur J, Yang HM, Cho HJ, Lee YS and Kim HS: Comparison of endothelialization and neointimal formation with stents coated with antibodies against CD34 and vascular endothelialcadherin. Biomaterials, 2012; 33: 8917-8927

14) Lampugnani MG, Resnati $M$, Raiteri $M$, Pigott $R$, Pisacane A, Houen G, Ruco LP and Dejana E: A novel endothelial-specific membrane protein is a marker of cellcell contacts. J Cell Biol, 1992; 118: 1511-1522

15) Wang XB, Chen XQ, Xing L, Mao C, Yu HX and Shen J: Blood compatibility of a new zwitterionic bare metal stent with hyperbranched polymer brushes. J Mat Chem B, 2013; 1: 5036-5044

16) Wang $X$, Miao J, Zhao H, Mao C, Chen $X$ and Shen J: Fabrication of nonbiofouling metal stent and in vitro studies on its hemocompatibility. J Biomater Appl, 2013;
29: $14-25$

17) Zhou M, Qiao W, Liu Z, Shang T, Qiao T, Mao C and Liu C: Development and in vivo evaluation of smalldiameter vascular grafts engineered by outgrowth endothelial cells and electrospun chitosan/poly (epsilon-caprolactone) nanofibrous scaffolds. Tissue Eng Part A, 2014; 20: 79-91

18) Zhou M, Liu Z, Liu C, Jiang X, Wei Z, Qiao W, Ran F, Wang W, Qiao T and Liu C: Tissue engineering of smalldiameter vascular grafts by endothelial progenitor cells seeding heparin-coated decellularized scaffolds. J Biomed Mater Res B Appl Biomater, 2012; 100: 111-120

19) Lee JH, Park Y, Choi JR, Lee EK and Kim HS: Comparisons of three automated systems for genomic DNA extraction in a clinical diagnostic laboratory. Yonsei Med J, 2010; 51: 104-110

20) Ferrans VJ, Spray TL, Billingham ME and Roberts WC: Structural changes in glutaraldehyde-treated porcine heterografts used as substitute cardiac valves. Transmission and scanning electron microscopic observations in 12 patients. Am J Cardiol, 1978; 41: 1159-1184

21) Richardson MR and Yoder MC: Endothelial progenitor cells: quo vadis? J Mol Cell Cardiol, 2011; 50: 266-272

22) Yoon CH, Hur J, Park KW, Kim JH, Lee CS, Oh IY, Kim TY, Cho HJ, Kang HJ, Chae IH, Yang HK, Oh BH, Park YB and Kim HS: Synergistic neovascularization by mixed transplantation of early endothelial progenitor cells and late outgrowth endothelial cells: the role of angiogenic cytokines and matrix metalloproteinases. Circulation, 2005; 112: 1618-1627

23) Lim WH, Seo WW, Choe W, Kang CK, Park J, Cho HJ, Kyeong S, Hur J, Yang HM, Cho HJ, Lee YS and Kim HS: Stent coated with antibody against vascular endothelial-cadherin captures endothelial progenitor cells, accelerates re-endothelialization, and reduces neointimal formation. Arterioscler Thromb Vasc Biol, 2011; 31: 2798-2805

24) Li D, Chen H, Glenn McClung W and Brash JL: LysinePEG-modified polyurethane as a fibrinolytic surface: Effect of PEG chain length on protein interactions, platelet interactions and clot lysis. Acta Biomater, 2009; 5: 1864-1871

25) Kim K, Shin K, Kim H, Kim C and Byun Y: In situ photopolymerization of a polymerizable poly(ethylene glycol)covered phospholipid monolayer on a methacryloyl-terminated substrate. Langmuir, 2004; 20: 5396-5402

26) Amiji $M$ and Park K: Surface modification of polymeric biomaterials with poly(ethylene oxide), albumin, and heparin for reduced thrombogenicity. J Biomater Sci Polym Ed, 1993; 4: 217-234

27) Smith RS, Zhang Z, Bouchard M, Li J, Lapp HS, Brotske GR, Lucchino DL, Weaver D, Roth LA, Coury A, Biggerstaff J, Sukavaneshvar S, Langer $\mathrm{R}$ and Loose C: Vascular catheters with a nonleaching poly-sulfobetaine surface modification reduce thrombus formation and microbial attachment. Sci Transl Med, 2012; 4: 153 ra132

28) Hayward JA and Chapman D: Biomembrane surfaces as models for polymer design: the potential for haemocompatibility. Biomaterials, 1984; 5: 135-142

29) Pareta RA, Reising AB, Miller T, Storey D and Webster TJ: Increased endothelial cell adhesion on plasma modi- 
fied nanostructured polymeric and metallic surfaces for vascular stent applications. Biotechnol Bioeng, 2009; 103: 459-471

30) Komatsu R, Ueda M, Naruko T, Kojima A and Becker AE: Neointimal tissue response at sites of coronary stenting in humans: macroscopic, histological, and immunohistochemical analyses. Circulation, 1998; 98: 224-233

31) Busch R, Strohbach A, Rethfeldt S, Walz S, Busch M, Petersen S, Felix $S$ and Sternberg K: New stent surface materials: the impact of polymer-dependent interactions of human endothelial cells, smooth muscle cells, and platelets. Acta Biomater, 2014; 10: 688-700

32) Shen L, Gong F, Tian W, Li W, Zhang F, Qian J, Sun A, Zou Y, Yang W and Ge J: Anti-inflammatory effects of arsenic trioxide eluting stents in a porcine coronary model.
Biomed Res Int, 2013; 2013: 937936

33) Sarkar R, Meinberg EG, Stanley JC, Gordon D and Webb RC: Nitric oxide reversibly inhibits the migration of cultured vascular smooth muscle cells. Circ Res, 1996; 78: 225-230

34) Freedman JE, Loscalzo J, Barnard MR, Alpert C, Keaney JF and Michelson AD: Nitric oxide released from activated platelets inhibits platelet recruitment. J Clin Invest, 1997; 100: 350-356

35) Liu S-Q, Li Z-L, Cao Y-X, Li L, Ma X, Zhao X-G, Kang A-Q, Liu C-H and Yuan B-X: Transfusion of autologous late-outgrowth endothelial cells reduces arterial neointima formation after injury. Cardiovasc Res, 2011; 90: 171181 